\title{
Field treatment of acute nerve function impairment in leprosy using a standardized corticosteroid regimen-first year's experience with 100 patients
}

\author{
R. P. CROFT*, J. H. RICHARDUS $\dagger$, \\ W. C. S. SMITH \\ *Danish-Bangladesh Leprosy Mission, P. O. Box 03, PO. Nilpha- \\ mari 5300, District Nilphamari, Bangladesh \\ $\dagger$ Department of Public Health, Erasmus University, Postbus 1738, \\ 3000DR Rotterdam, The Netherlands \\ $\ddagger$ Department of Public Health, University of Aberdeen, Aberdeen \\ $A B 9$ 2ZD, Scotland
}

\section{Accepted for publication 7 August 1997}

Summary In this study, a fixed regimen of prednisolone for the treatment of acute nerve function impairment (NFI) in leprosy patients was developed and introduced at field level in one area (Thakurgaon) of the Danish-Bangladesh Leprosy Mission's field in NW Bangladesh. The assessment, management and follow-up of patients was undertaken by leprosy control supervisors and physiotechnicians.

One hundred patients were treated and followed up 6-8 months after completion of a 4-month course of prednisolone. At a level of change of 2 points (where a change of at least 2 points in the motor/sensory score was taken to indicate a change of status, i.e. full or partial recovery, or deterioration), 42/65 $(64.6 \%)$ patients with sensory loss experienced some sensory recovery at completion of prednisolone treatment, and $40 / 65(61.5 \%)$ at 6-8 months' follow-up. $41 / 85(48 \cdot 3 \%)$ of patients with motor loss experienced improvement, and $42 / 85(49 \cdot 4 \%)$ at follow-up. Analysis of the mean scores at start of prednisolone treatment, completion and at follow-up using Student's $t$-test showed highly significant $(p<0 \cdot 001)$ differences between scores before and after treatment. The benefit is maintained as seen after a period of $6-8$ months follow-up.

It was concluded that treatment of acute nerve function impairment at field level by paramedical workers, using a standardized regimen of prednisolone is feasible, practical and effective.

\section{Introduction}

In many leprosy control programmes, treatment of leprosy reactions using corticosteroids 
is confined to a hospital setting. Unfortunately, a proportion of patients who would benefit from corticosteroid administration are for various reasons unable or unwilling to be admitted to hospital. As a result they go on to develop nerve function impairment (NFI) with resulting disability and handicap. This problem was phrased by BecxBleumink et al. as follows: 'When the management of patients on corticosteroids is the responsibility of medical officers only, we will deprive many patients of adequate treatment for their reactions. ' A recent study of a cohort of new patients in Bangladesh that started MDT in 1990 shows that over a third of cases with recent NFI were not treated with corticosteroids for the above reason. ${ }^{2}$ Introduction of treatment in the field of recent NFI using standardized corticosteroid regimens has been hesitant. Organizational and logistic problems are one reason, reservations concerning side-effects of corticosteroids, and placing the responsibility of their management into the hands of paramedical workers, another.

It is well known that corticosteroids are effective in the treatment of leprosy reactions and acute NFI in leprosy. ${ }^{1,3-7}$ It is generally agreed that in order to be effective, corticosteroids must be administered within 6 months of an episode of NFI. ${ }^{1,8}$ As stated above, attention has been drawn to the need for such treatment to be given by suitably trained field workers in order for the maximum number of patients to receive benefit. ${ }^{1,9}$

Several standardized or semi-standardized regimens for the treatment of NFI have been proposed using prednisolone. For example, $40 \mathrm{mg}$ /day tapering over 12 weeks for paucibacillary (PB) patients and 20 weeks for multibacillary (MB) patients. ${ }^{9}$ Another regimen recommended is $25 \mathrm{mg}$ prednisolone daily, reducing by $5 \mathrm{mg}$ per month. ${ }^{6}$ For the latter regimen it was recommended that the starting dose should be higher for 'severe reactions'.

All of the studies referred to above comment on the absence of serious side-effects of prednisolone in relatively long courses. A recent meta-analysis reviewing 93 articles and 6602 patients found that peptic ulceration was not significantly associated with prolonged steroid use. ${ }^{10}$ In the meta-analysis, a mean daily dose of 35-mg prednisolone for a mean duration of 64 days was given - comparable to the courses used for the treatment of leprosy reactions. ${ }^{11}$ Other side-effects including diabetes, hypertension, psychosis and dermatological side-effects were found to be significantly associated, but bacterial sepsis, osteoporosis and tuberculosis while occurring more frequently in the treatment group, did not achieve statistical significance. Overall, a picture of relative safety emerged from this meta-analysis.

In 1994 the Danish-Bangladesh Leprosy Mission (DBLM) began with the implementation of a fully field-based programme of the treatment of leprosy reactions and acute NFI. The decision to give corticosteroids to individual patients was delegated to the lowest appropriate level, that of leprosy control supervisor (LCS) and physiotechnician (PT). A protocol for management of reactions was developed by a committee, training provided, and a 7-month pilot programme initiated. This study reports on the outcome of this initial programme after the first year's experience.

\section{Methods}

LOCATION

The study was conducted at the Danish-Bangladesh Leprosy Mission (DBLM) in 
Nilphamari, in NW Bangladesh. DBLM is a private organization involved in a vertical leprosy programme situated in a highly endemic area (prevalence: 5/1000). ${ }^{12}$ The field programme is geographically divided into three 'fields', each with separate reporting. One area, the Thakargaon field, was selected for this study. It covers the two districts of Thakargaon and Panchagar with a total area of $3,214 \mathrm{~km}^{2}$ and 1,7 million population (1991 census).

\section{ORGANIZATIONAL STRUCTURE}

The DBLM Thakargaon field is divided into 6 'blocks', each with its own staffing of leprosy control assistants (LCA) who work under the direction of a leprosy control supervisor (LCS), responsible for that block. In turn, the LCS relates to the leprosy control officer (LCO) who is responsible for the entire field. The LCO relates directly to the field director, who is a medical officer. In addition, there are physiotechnicians (PT) assigned to the field who visit on every clinic day and who are involved in nerve function testing, the teaching of special exercises and health education. New leprosy cases are charted by LCAs who also take skin smears. The cases are then confirmed by the LCS, and MDT is given at his direction. All cases at every clinic visit (during multidrug therapy (MDT) and surveillance) have sensory testing and quick muscle testing carried out by the LCA. If any abnormality is found, the case is referred to the PT and LCS for confirmation. Equivocal results were not accepted for corticosteroid treatment and in such cases were reassessed the following month.

\section{NERVE FUNCTION TESTING}

Sensory testing was carried out using a ball-point pen as described by Watson. ${ }^{13}$ Testing took place at 12 standard points on each hand palm and 11 standard points on each foot sole. Either partial or complete anaesthesia was taken as a positive finding. The sensory score is calculated by counting the number of sensory points which were abnormal. Motor function testing of the facial, radial, ulnar, median and lateral popliteal nerves was carried out by means of 'quick muscle testing' (QMT) and graded according to a revised MRC scale ${ }^{14}$ (Table 1). The regular MRC score was reversed so that zero always indicated normality for both motor or sensory testing. The reversed score is referred to as the DBLM score. Details of muscles tested are also given in Table 1. Each muscle or muscle group tested is assigned a DBLM score up to a maximum of 5 .

Corneal sensation testing was performed in those patients who were observed to blink inf requently (less than 5 times per minute), but the evaluation of this parameter is not included in this study.

\section{ACUTE NFI TREATMENT PROTOCOL}

The complete guidelines as used for this study are reproduced in the Appendix. According to these guidelines leprosy reactions and NFI are graded according to severity and treatment assigned accordingly. Patients with signs of acute NFI were given 40-mg prednisolone daily and tapered off over 4 months in the field. This was 
Table 1. Muscle strength scoring (MRC scale ${ }^{14}$ )

\begin{tabular}{lcc}
\hline Muscle strength finding & MRC score & DBLM score \\
\hline Full ROM & \\
& & \\
Full full resistance & 5 & 0 \\
Full ROM, noduced resistance & 4 & 1 \\
Reduced ROM, some joint movement & 3 & 2 \\
Flicker only & 2 & 3 \\
Full paralysis & 1 & 4 \\
& 0 & 5 \\
\hline
\end{tabular}

\footnotetext{
${ }^{1} \mathrm{ROM}=$ range of movement.

Details of muscles tested in quick muscle test:

Facial nerve: $\quad$ Tight eye closure (orbicularis oculi)—MRC scale Lid gap on light eye closure $(\mathrm{mm})$

Ulnar nerve:

Median nerve:

Abduction of little finger

Radial nerve:

Abduction of thumb

Wrist extension

Lateral popliteal nerve: Dorsiflexion of foot; Eversion of foot
}

defined as the reduction by 1 point in the MRC muscle strength grade of any of the movements routinely tested in the QMT; the loss of 1 standard sensory point on the hands or feet; or the development of corneal anaesthesia. Acute was taken to mean occurring within the previous 6 months. Other signs of leprosy reaction or NFI may or may not have been present, e.g. inflamed skin patches, painful nerves.

Patients with acute NFI according to the criteria of DBLM grade 2 (see Appendix) seen between July 1994 and January 1995 were included in this study. There were no patients with impairments according to DBLM grade 3, although patients whose nerve function deteriorated after starting field prednisolone were admitted during treatment. Patients with signs of Type I reaction or neuritis without signs of NFI (DBLM grades 1a and $1 \mathrm{~b}$ ) were excluded, even if they were treated with prednisolone. Out of the initial group of 103 , one died and two were lost to follow-up. A total of 100 patients were included in the study group.

Table 2. General data of 100 patients who received a standardized regimen of prednisolone in the field

\begin{tabular}{|c|c|c|c|c|c|c|c|c|c|c|}
\hline \multirow{2}{*}{$\begin{array}{l}\text { Age in years } \\
\text { at diagnosis } \\
\text { acute NFI }\end{array}$} & \multicolumn{2}{|c|}{ Male } & \multicolumn{2}{|c|}{ Female } & \multicolumn{3}{|c|}{ Both sexes } & \multicolumn{3}{|c|}{ Status } \\
\hline & PB & MB & PB & MB & $\mathrm{PB}$ & MB & Tot & New pt & On MDT & RFT pt \\
\hline $0-9$ & 0 & 0 & 0 & 1 & 0 & 1 & 1 & 1 & 0 & 0 \\
\hline $10-19$ & 3 & 5 & 1 & 4 & 4 & 9 & 13 & 3 & 8 & 2 \\
\hline $20-29$ & 3 & 10 & 3 & 2 & 6 & 12 & 18 & 4 & 8 & 6 \\
\hline $30-39$ & 4 & 16 & 4 & 7 & 8 & 23 & 31 & 9 & 15 & 7 \\
\hline $40-49$ & 1 & 8 & 1 & 7 & 2 & 15 & 17 & 2 & 11 & 4 \\
\hline $50-59$ & 2 & 6 & 2 & 4 & 4 & 10 & 14 & 8 & 3 & 3 \\
\hline$>60$ & 2 & 3 & 0 & 1 & 2 & 4 & 6 & 2 & 3 & 1 \\
\hline Total & 15 & 48 & 11 & 26 & 26 & 74 & 100 & 29 & 48 & 23 \\
\hline
\end{tabular}


FOLLOW-UP

Data relating to NFI was collected at the followings times:

0 Before the start of the acute NFI episode (usually at registration).

I At the start of field prednisolone treatment.

II At completion of field prednisolone treatment.

III 6 to 8 months after completion of field prednisolone treatment.

(The measurement of NFI scores before starting field prednisolone treatment was not possible in new patients presenting in reaction or with acute NFI.)

\section{DEFINITIONS OF OUTCOME}

Full recovery Restoration of sensory or motor score to zero (normality).

Partial recovery Partial improvement in sensory or motor score.

Same

No overall change in sensory or motor score.

Deterioration Deterioration in sensory or motor score.

\section{Results}

Table 2 shows the general data of the 100 patients who received a standardized regimen of prednisolone in the field. The mean age of patients was $35 \cdot 3$ years (median: $34 \cdot 5$ years, range: $8-70$ years). The distribution of study patients according to the Ridley-Jopling classification was as follows: BT: 64; BB: 12; BL: 13; LL: 7; PN: 4.

The outcome of sensory function amongst the study group is shown in Table 3 , the outcome of motor function is shown in Table 4. Outcome has been expressed at different 'sensitivity levels'. Where a change of $\geq 1$ point in the sensory score was taken as

Table 3. Outcome of sensory function amongst study group patients with acute sensory loss expressed at three levels of sensitivity $(n=65)$

\begin{tabular}{|c|c|c|c|c|c|c|c|c|c|c|c|c|}
\hline \multirow[b]{3}{*}{ Outcome } & \multicolumn{6}{|c|}{ At end of prednisolone therapy } & \multicolumn{6}{|c|}{$\begin{array}{l}6-8 \text { months after completion of } \\
\text { prednisolone therapy }\end{array}$} \\
\hline & \multicolumn{3}{|c|}{$\begin{array}{c}\text { Outcome at } 3 \\
\text { sensitivity } \\
\text { levels* } \\
\text { (absolute) }\end{array}$} & \multicolumn{3}{|c|}{$\begin{array}{c}\text { Outcome at } 3 \\
\text { sensitivity } \\
\text { levels* } \\
(\%)\end{array}$} & \multicolumn{3}{|c|}{$\begin{array}{c}\text { Outcome at } 3 \\
\text { sensitivity } \\
\text { levels* } \\
\text { (absolute) }\end{array}$} & \multicolumn{3}{|c|}{$\begin{array}{c}\text { Outcome at } 3 \\
\text { sensitivity } \\
\text { levels* } \\
(\%)\end{array}$} \\
\hline & $\geq 1$ & $\geq 2$ & $\geq 3$ & $\geq 1$ & $\geq 2$ & $\geq 3$ & $\geq 1$ & $\geq 2$ & $\geq 3$ & $\geq 1$ & $\geq 2$ & $\geq 3$ \\
\hline Full & 25 & 19 & 16 & $38 \cdot 5$ & $29 \cdot 2$ & $24 \cdot 6$ & 25 & 19 & 15 & $38 \cdot 5$ & $29 \cdot 2$ & $23 \cdot 1$ \\
\hline Partial & 28 & 23 & 16 & $43 \cdot 1$ & $35 \cdot 4$ & $24 \cdot 6$ & 25 & 21 & 18 & $38 \cdot 5$ & $32 \cdot 3$ & $27 \cdot 7$ \\
\hline Same & 6 & 21 & 31 & $9 \cdot 2$ & $32 \cdot 3$ & $47 \cdot 7$ & 4 & 18 & 27 & $6 \cdot 1$ & $27 \cdot 7$ & $41 \cdot 5$ \\
\hline Deteriorated & 6 & 2 & 2 & $9 \cdot 2$ & $3 \cdot 1$ & $3 \cdot 1$ & 11 & 7 & 5 & $16 \cdot 9$ & $10 \cdot 8$ & $7 \cdot 7$ \\
\hline Total & 65 & 65 & 65 & 100 & 100 & 100 & 65 & 65 & 65 & 100 & 100 & 100 \\
\hline
\end{tabular}

*Sensitivity levels Outcome is expressed at 3 sensitivity levels. These indicate numbers of patients whose sensory scores changed either $\geq 1, \geq 2$ or $\geq 3$ points relative to the score at start of prednisolone therapy. 
Table 4. Outcome of motor function amongst study group patients with acute motor loss expressed at three levels of sensitivity $(n=85)$

\begin{tabular}{|c|c|c|c|c|c|c|c|c|c|c|c|c|}
\hline \multirow[b]{3}{*}{ Outcome } & \multicolumn{6}{|c|}{ At end of prednisolone therapy } & \multicolumn{6}{|c|}{$\begin{array}{l}\text { 6-8 months after completion of } \\
\text { prednisolone therapy }\end{array}$} \\
\hline & \multicolumn{3}{|c|}{$\begin{array}{c}\text { Outcome at } 3 \\
\text { sensitivity } \\
\text { levels* } \\
\text { (absolute) }\end{array}$} & \multicolumn{3}{|c|}{$\begin{array}{c}\text { Outcome at } 3 \\
\text { sensitivity } \\
\text { levels* } \\
(\%)\end{array}$} & \multicolumn{3}{|c|}{$\begin{array}{c}\text { Outcome at } 3 \\
\text { sensitivity } \\
\text { levels* } \\
\text { (absolute) }\end{array}$} & \multicolumn{3}{|c|}{$\begin{array}{c}\text { Outcome at } 3 \\
\text { sensitivity } \\
\text { levels* } \\
(\%)\end{array}$} \\
\hline & $\geq 1$ & $\geq 2$ & $\geq 3$ & $\geq 1$ & $\geq 2$ & $\geq 3$ & $\geq 1$ & $\geq 2$ & $\geq 3$ & $\geq 1$ & $\geq 2$ & $\geq 3$ \\
\hline Full & 52 & 27 & 14 & $61 \cdot 2$ & $31 \cdot 8$ & $16 \cdot 5$ & 60 & 34 & 18 & $70 \cdot 6$ & $40 \cdot 0$ & $21 \cdot 2$ \\
\hline Partial & 27 & 14 & 8 & $31 \cdot 8$ & $16 \cdot 5$ & $9 \cdot 4$ & 17 & 8 & 6 & $20 \cdot 0$ & $9 \cdot 4$ & $7 \cdot 1$ \\
\hline Same & 4 & 42 & 63 & $4 \cdot 7$ & $49 \cdot 4$ & $74 \cdot 1$ & 3 & 39 & 58 & $3 \cdot 5$ & $45 \cdot 9$ & $68 \cdot 2$ \\
\hline Deteriorated & 2 & 2 & 0 & $2 \cdot 4$ & $2 \cdot 4$ & 0 & 5 & 4 & 3 & $5 \cdot 9$ & $4 \cdot 7$ & $3 \cdot 5$ \\
\hline Total & 85 & 85 & 85 & 100 & 100 & 100 & 85 & 85 & 85 & 100 & 100 & 100 \\
\hline
\end{tabular}

*Sensitivity levels Outcome is expressed at 3 sensitivity levels. These indicate numbers of patients whose motor scores changed either $\geq 1, \geq 2$ or $\geq 3$ points relative to the score at start of prednisolone therapy.

significant, a total of $81.6 \%$ of patients showed sensory improvement after completion of prednisolone therapy ( $38.5 \%$ with full recovery), a percentage maintained with $77 \%$ improved (38.5\% full) after $6-8$ months of follow-up. With a change of $\geq 2$ points in the sensory score, this was $64 \cdot 6 \%(29 \cdot 2 \%$ full $)$ at completion of therapy and $61 \cdot 5 \%(29 \cdot 2 \%$ full) at 6-8 months; at the $\geq 3$-point change in sensory score there was $49 \cdot 2 \%(24 \cdot 6 \%$ full) at end of therapy and 50.8\% (23.1\% full) at follow-up. Thus, the level of improvement in sensory function was of the order of $50-60 \%$ at more conservative levels of sensitivity, a level which was maintained 6-8 months after the end of

Table 5. Total sensory scores and mean sensory scores at diagnosis of NFI (I), completion of prednisolone therapy (II), and at follow-up (III), with significance of mean differences calculated using $t$-test. Complete anaesthesia of hands and feet in one patient would score 46, with a best possible total score of 0

\begin{tabular}{|c|c|c|c|c|c|c|c|c|c|c|}
\hline \multirow[b]{2}{*}{ Category } & \multirow[b]{2}{*}{$n$} & \multicolumn{3}{|c|}{ Total sensory scores } & \multicolumn{3}{|c|}{ Mean sensory scores } & \multicolumn{3}{|c|}{$\begin{array}{c}p \text {-value of mean } \\
\text { differences }\end{array}$} \\
\hline & & I & II & III & I & II & III & I-II & I-III & II-III \\
\hline Male & 37 & 401 & 187 & 227 & $10 \cdot 84$ & $5 \cdot 05$ & $6 \cdot 14$ & $<\cdot 001$ & $<\cdot 001$ & $\cdot 347$ \\
\hline Female & 28 & 228 & 122 & 133 & $8 \cdot 14$ & $4 \cdot 36$ & $4 \cdot 75$ & .001 & $\cdot 042$ & .778 \\
\hline PB & 14 & 149 & 81 & 71 & $10 \cdot 64$ & $5 \cdot 79$ & $5 \cdot 07$ & .024 & .016 & $\cdot 325$ \\
\hline MB & 51 & 480 & 228 & 289 & $9 \cdot 41$ & $4 \cdot 47$ & $5 \cdot 67$ & $<\cdot 001$ & .002 & .278 \\
\hline$<1$ month* & 28 & 300 & 180 & 133 & $10 \cdot 71$ & $6 \cdot 43$ & $4 \cdot 75$ & $<\cdot 001$ & $<\cdot 001$ & $\cdot 109$ \\
\hline 1-3 months* & 26 & 267 & 77 & 164 & $10 \cdot 27$ & $2 \cdot 96$ & $7 \cdot 31$ & $<\cdot 001$ & $\cdot 024$ & $\cdot 058$ \\
\hline 4-6 months* & 11 & 62 & 52 & 63 & $5 \cdot 64$ & $4 \cdot 73$ & $5 \cdot 73$ & $\cdot 453$ & .957 & .484 \\
\hline All & 65 & 629 & 309 & 360 & $9 \cdot 68$ & $4 \cdot 75$ & $5 \cdot 54$ & $<\cdot 001$ & $<\cdot 001$ & $\cdot 372$ \\
\hline
\end{tabular}

*Duration of NFI. 
prednisolone treatment. Comparison of mean differences in sensory scores calculated bef ore and after prednisolone therapy (Table 5) shows highly significant differences for mean scores both immediately after prednisolone and at 6-8 months' follow-up using the Student $t$-test $(p<0 \cdot 001)$. The only exception was for the small group of patients with NFI of 4-6 months' duration $(n=11)$ where there was no significant differences between the mean scores before treatment and at either time after treatment. Although this number is too small to draw statistical conclusions from, it suggests that there may be less recovery in patients with more established NFI. There was no significant difference between mean sensory scores immediately after prednisolone treatment and at 6-8 months' follow-up ( $p=0 \cdot 372)$, indicating that sensory recovery is maintained.

Turning to motor recovery, there is also a good level of response, but less marked than for sensory outcome. At the $\geq 1$ point change of motor function score there is a $93 \%$ $(61 \cdot 2 \%$ full) overall improvement at the end of prednisolone therapy and $90 \cdot 6 \%(70 \cdot 6 \%$ full) at end of follow-up. However, at the $\geq 2$-point level it is $48 \cdot 3 \%$ (31.8\% full) and $49 \cdot 4 \%$ (40\% full) respectively. At the $\geq 3$ level it is $25 \cdot 9 \%(16 \cdot 5 \%$ full) and $28 \cdot 3 \%(7 \cdot 1 \%$ full) respectively. Thus the level of motor recovery was in the range $25-50 \%$ at the $\geq 2$ or $\geq 3$ point levels in change of motor function score. Again, analysis of mean differences using the Student $t$-test between mean motor scores before and after prednisolone treatment showed a highly significant difference with $p<\cdot 001$. Interestingly, the longer duration NFI group (4-6 months' duration) did show a significant difference in mean scores before and after treatment $(p=0 \cdot 001)$, unlike the parallel sensory group. Again, there was no significant difference between mean motor scores immediately after prednisolone treatment and at 6-8 months' follow-up $(p=0 \cdot 361)$, indicating that motor recovery, like sensory recovery, is maintained.

\section{Discussion}

This study is primarily concerned with the feasibility and effectiveness of treating acute NFI with a standardized regimen of prednisolone in the field. A single standardized regimen for the treatment of NFI was developed based on the recommendations made by Rose \& Waters ${ }^{9}$ as well as Becx-Bleumink. ${ }^{1}$ This was taught to field staff in the DBLM Thakurgaon field and implemented, using experienced leprosy control supervisors and physiotechnicians as the key persons at field level to assess patients and give treatment.

Results of the field treatment of NFI with prednisolone were analysed in two separate ways: the first method described change in nerve function in terms of full and partial recovery, same (no change) and deterioration, using three different levels of sensitivity in defining a relevant change in sensory or motor function score. In the second method mean differences of total sensory and motor function scores at the time of diagnosis, completion of prednisolone therapy and after follow-up were compared and statistically analysed. Both approaches demonstrate marked improvement in both sensory and motor function, even when applying the very strict criteria of a change of $\geq 3$ points in the sensory and motor function scores. This conclusion applies to the overall study group. Only in patients with NFI of 4 to 6 months duration, improvement in the sensory scores in marginal, if at all (Table 5). There does seem to be 
Table 6. Total motor scores and mean motor scores at diagnosis of NFI(I), completion of prednisolone therapy (II), and at follow-up (III), with significance of mean differences calculated using $t$-test. Complete motor paralysis of hands and feet in one patient would score 25 , with a best possible total score of 0

\begin{tabular}{|c|c|c|c|c|c|c|c|c|c|c|}
\hline \multirow[b]{2}{*}{ Category } & \multirow[b]{2}{*}{$n$} & \multicolumn{3}{|c|}{ Total motor scores } & \multicolumn{3}{|c|}{ Mean motor scores } & \multicolumn{3}{|c|}{$\begin{array}{l}p \text {-value of mean } \\
\text { differences }\end{array}$} \\
\hline & & I & II & III & I & II & III & I-II & I-III & II-III \\
\hline Male & 56 & 171 & 64 & 72 & 3.05 & $1 \cdot 14$ & $1 \cdot 29$ & $<\cdot 001$ & $<\cdot 001$ & $\cdot 453$ \\
\hline Female & 29 & 71 & 22 & 28 & $2 \cdot 45$ & $0 \cdot 76$ & 0.97 & $<\cdot 001$ & .001 & .607 \\
\hline PB & 20 & 48 & 12 & 13 & $2 \cdot 40$ & $0 \cdot 60$ & 0.65 & $<\cdot 001$ & $<\cdot 001$ & $\cdot 834$ \\
\hline MB & 65 & 194 & 74 & 87 & $2 \cdot 98$ & $1 \cdot 14$ & $1 \cdot 34$ & $<\cdot 001$ & $<\cdot 001$ & $\cdot 375$ \\
\hline$<1$ month* & 34 & 94 & 36 & 48 & $2 \cdot 76$ & $1 \cdot 06$ & $1 \cdot 41$ & $<\cdot 001$ & .002 & $\cdot 321$ \\
\hline $1-3$ months* & 37 & 107 & 36 & 34 & $2 \cdot 89$ & 0.97 & 0.92 & $<\cdot 001$ & $<\cdot 001$ & .827 \\
\hline 4-6 months* & 14 & 41 & 14 & 18 & $2 \cdot 93$ & $1 \cdot 00$ & 1.29 & $<.001$ & $<\cdot 001$ & .218 \\
\hline All & 85 & 242 & 86 & 100 & $2 \cdot 85$ & $1 \cdot 01$ & $1 \cdot 18$ & $<\cdot 001$ & $<\cdot 001$ & $\cdot 361$ \\
\hline
\end{tabular}

*Duration of NFI.

improvement in the motor scores in this group (Table 6). The size of the study was too small to identify risk factors for nerve damage and to look at the response of subsets of patients to treatment. However, that is the subject of a large prospective cohort study into acute nerve damage now running in DBLM (Bangladesh acute nerve damage study).

The results of this study compare well with those of Van Brakel \& Khawas. $^{7}$ In that study touch sensibility testing was performed using a nylon monofilaments giving a force of $10 \mathrm{~g}$ for the hands, and a thicker one giving a force of $75 \mathrm{~g}$ for the sole of the foot, whereas DBLM uses the ball-point pen in the field. The criteria they used for change in sensory and motor function are a difference of more than 1 point (or $\geq 2$ ) on the touch sensibility test (TST) or voluntary muscle test (VMT). Van Brakel \& Khawas analyse in depth changes seen in individual nerves and also describe time trends and prognostic factors, elements outside the scope of the study presented in this paper. Nevertheless, the overall picture of improvement in sensory scores (app. 65\%), and motor function scores (app. $50 \%$ ) at a change of $\geq 2$ point in score, is similar. The improvement was maintained over a follow-up period of more than 6 months.

A number of patients experienced deterioration in nerve function during the period, including a few patients who initially fully recovered. All of these patients required a second course of prednisolone or a hospital admission. However, given that a fixed regimen was used (the field staff were not given freedom to alter it at will) the results can still be considered as very satisfactory.

In this study, no cases of peptic ulcer, TB, sepsis or psychosis occurred. Blood pressure was not routinely measured by field staff and urine glucose was also not tested. Dermatological side-effects including acne, tinea corporis and cushingoid fat redistribution occurred only in a small number of patients. The overall experience has been very positive with the field staff enthusiastic towards the programme despite the increased workload for them. They reported good compliance from patients once they understood that they were avoiding a hospital admission; positive feedback from patients recovering lost nerve 
function; and the staff themselves felt happy about their increased responsibility. Since the field treatment of reactions has been extended to the whole of DBLM there has been a marked drop in hospital admissions, freeing beds which are now being used for an increasingly busy reconstructive surgery programme.

We share the conclusion of Van Brakel \& $\mathrm{Khawas}^{7}$ that further research is needed to optimize the results of treatment of acute NFI. There are still too many patients for whom the present detection and treatment options are not sufficient, and who remain with impairments after successful treatment of their leprosy infection with MDT. On the other hand we are strongly convinced that as a first step, and pending further improvements in detection and therapy, the present knowledge and possibilities of early detection and treatment of NFI should be made available for all leprosy patients. This study shows that field treatment of NFI with a standardized regimen of prednisolone, administered by paramedical staff is feasible, practical and effective.

\section{Acknowledgments}

The authors wish to acknowledge the help and cooperation given by all the field staff working from DBLM Thakurgaon. In particular, Mr Kiron Chakrabarty and Mr Yakub Ali, physiotechnicians, gave long hours of overtime to complete the domiciliary follow-up required for this study.

\section{References}

${ }^{1}$ Becx-Bleumink M, Berhe D, Mannet je W. The management of nerve damage in the leprosy control services, Lepr Rev 1990; 61: 1-11.

2 Richardus JH, Finlay K, Croft RP, Smith WCS. Nerve function impairment in leprosy at diagnosis and at completion of MDT: a retrospective cohort study of 786 patients in Bangladesh. Lepr Rev 1996; 67: 297305.

3 Becx-Bleumink M, Berhe D. Occurrence of reactions, their diagnosis and management in leprosy patients with MDT; experience in the Leprosy Control Programme of the All Africa Leprosy and Rehabilitation Training Centre (ALERT) in Ethiopia. Int J Lepr 1992; 60: 173-84.

${ }^{4}$ Kiran KU, Stanley JNA, Pearson JMH. The outpatient treatment of nerve damage in patients with borderline leprosy using a semistandardized steroid regimen. Lepr Rev 1985; 56: 127-34.

5 Lockwood DNJ, Vinayakumar S, Stanley JNA, McAdam KPWL, Colston MJ. Clinical features and outcome of reversal (type 1) reactions in Hyderabad, India. Int J Lepr 1993; 61: 8-15.

6 Srinivasan H, Rao KS, Shanmugam N. Steroid therapy in recent "quiet nerve paralysis" in leprosy. Lepr Ind 1982; 54: 412-9.

7 Van Brakel WH, Khawas IB. Nerve function impairment in leprosy: an epidemiological and clinical study Part 2: Results of steroid treatment. Lepr Rev 1996; 67: 104-18.

${ }^{8}$ Lienhardt C, Fine PE. Type 1 reaction, neuritis and disability in leprosy. What is the current epidemiological situation? Lepr Rev 1994; 65: 9-33.

9 Rose P, Waters MFR. Reversal reactions in leprosy and their management. Lepr Rev 1991; 62: 113-21.

10 Conn HO, Poynard T. Corticosteroids and peptic ulcer: meta-analysis of adverse events during steroid therapy. J Int Med 1994; 236: 619-32.

11 Richardus JH, Smith WCS. The risk of standardised regimens of corticosteroids for the treatment of leprosy reactions in the field. Lepr Rev 1995: 66: 328-9.

12 Richardus JH, Croft RP. Estimating the size of the leprosy problem: the Bangladesh experience. Lepr Rev 1995; 66: 158-64.

${ }^{13}$ Watson, JM. Essential action to minimize disability in leprosy patients. The Leprosy Mission International, 1988.

${ }^{14}$ MRC: Aids to the investigation of peripheral nerve injuries, MRC Memo no. 7, London, HMSO. 


\section{Appendix}

Table showing treatment regimens for Type I reactions/neuritis

Action

\section{DBLM Grade la}

- Reacting skin patch not overlying truncal nerve

- Mild nerve pain only

- No sensory or motor loss

\section{DBLM Grade 1b}

- Reacting skin patch not responding to Aspirin

- Reacting skin patch overlying truncal nerve or any big facial patch

- Cutaneous neuritis

- No sensory or motor loss

\section{DBLM Grade 2}

- Grade $1 \mathrm{~b}$ pt not responding to low-dose Prednisolone

- New sensory loss

- New motor loss to not less than MRC grade 3

- Moderate/severe painful nerve trunk

- Ulcerating/extensive skin reaction

- Not pregnant/no ulcer present

- Eye not in danger ${ }^{1}$

- Sensory/motor score must have newly decreased by at least 1 point

\section{DBLM Grade 3}

- Grade 2 patient not responding to full-dose prednisolone

- New motor loss to less than MRC grade 3

- Eye in danger ${ }^{1}$

- Pregnant patient/patient with ulcer with reaction needing steroids

- Any seriously ill patient

- Patient with compelling social reasons
- Aspirin for up to 3 weeks (or PARACETAMOL if problems)

- ST/QMT by LCA

- Weekly follow-up and medicine supply

- If no improvement, grade as DBLM $1 b$

- Low dose prednisolone (not reproduced here)

- ST/QMT by LCA

- Body chart if RFT

- Skin smear if RFT

- Weekly follow-up 1 month, then 2 weekly

- If no improvement, grade as DBLM grade 2

- Full-dose type 1 prednisolone (see dose regimen)

- ST/VMT by physiotechnician

- Body chart if skin reaction present

- Skin smear if RFT

- Record level of pain ${ }^{2}$

- Fill up reaction treatment record sheet

- Rest, splinting, warmth, exercises as appropriate by PT/LCS

- Weekly review at home 1 month, then 2 weekly

- $\mathrm{ST} / \mathrm{VMT}$ by PT at clinic on visits 1,2 , last (at least)

- If patient worsens, grade as DBLM grade 3

- Admit to hospital

- Patients refusing to go to hospital can be treated in the field using full-dose prednisolone except if pregnant

\footnotetext{
${ }^{1}$ Eye in danger: New development of lid gap, loss of blinking reflex or corneal anaesthesia.

${ }^{2}$ Pain level: Severe—disturbs sleep; Moderate-sleep OK, painful at work; Mild—slight problem; Tender painful on pressure only.
}

Dosage of prednisolone used in treatment of acute nerve damage ('Full dose prednisolone')

\begin{tabular}{|c|c|c|c|c|c|c|c|}
\hline \multicolumn{2}{|c|}{ Adult $>35 \mathrm{~kg}$} & \multicolumn{2}{|c|}{$\begin{array}{l}\text { Small adult } \\
\text { child } 10-14 \mathrm{y} \\
20-35 \mathrm{~kg}\end{array}$} & \multicolumn{2}{|c|}{$\begin{array}{c}\text { Child 6-9y } \\
15-19 \mathrm{~kg}\end{array}$} & \multicolumn{2}{|c|}{$\begin{array}{l}\text { Child }<6 \mathrm{y} \\
<15 \mathrm{~kg}\end{array}$} \\
\hline $40 \mathrm{mg} / \mathrm{d}$ & 4 wks & $30 \mathrm{mg} / \mathrm{d}$ & 4 wks & $20 \mathrm{mg} / \mathrm{d}$ & 4 wks & $10 \mathrm{mg} / \mathrm{d}$ & $4 \mathrm{wks}$ \\
\hline $30 \mathrm{mg} / \mathrm{d}$ & $2 \mathrm{wks}$ & $25 \mathrm{mg} / \mathrm{d}$ & 2 wks & $15 \mathrm{mg} / \mathrm{d}$ & 2 wks & $5 \mathrm{mg} / \mathrm{d}$ & 4 wks \\
\hline $25 \mathrm{mg} / \mathrm{d}$ & 2 wks & $20 \mathrm{mg} / \mathrm{d}$ & 2 wks & $10 \mathrm{mg} / \mathrm{d}$ & 2 wks & $2.5 \mathrm{mg} / \mathrm{d}$ & $2 \mathrm{wks}$ \\
\hline $20 \mathrm{mg} / \mathrm{d}$ & 2 wks & $15 \mathrm{mg} / \mathrm{d}$ & 2 wks & $5 \mathrm{mg} / \mathrm{d}$ & 2 wks & & \\
\hline $15 \mathrm{mg} / \mathrm{d}$ & 2 wks & $10 \mathrm{mg} / \mathrm{d}$ & 2 wks & & & & \\
\hline $10 \mathrm{mg} / \mathrm{d}$ & 2 wks & $5 \mathrm{mg} / \mathrm{d}$ & 2 wks & & & & \\
\hline $5 \mathrm{mg} / \mathrm{d}$ & $2 \mathrm{wks}$ & & & & & & \\
\hline Total & 16 wks & Total & 14 wks & Total & 10 wks & Total & 10 wks \\
\hline
\end{tabular}

